Journal of Animal and Veterinary Advances 10 (5): 627-634, 2011

ISSN: $1680-5593$

(C) Medwell Journals, 2011

\title{
Ecological Characteristics of Macrobenthic Communities in the Chaohu Lake Basin and Their Relationship with Environmental Factors
}

\author{
${ }^{1}$ Feng Gao, ${ }^{2}$ Jiancai Deng, ${ }^{2} \mathrm{Zhibo} \mathrm{Xu},{ }^{2} \mathrm{Yi}$ Ning, ${ }^{2} \mathrm{H}$ ongbin Yin and ${ }^{2} \mathrm{Junfeng}$ Gao \\ ${ }^{1}$ State Key Laboratory of Lake Science and Environment, Nanjing Institute of Geography and Limnology, \\ Chinese Academy of Science, Nanjing 210008, China \\ ${ }^{2}$ Graduate School of the Chinese, Academy of Science, Beijing 100039, China
}

\begin{abstract}
Researchers investigated the structural characteristics and the biodiversity of macrobenthic communities and their relationships with environmental factors in the Chaohu Lake Basin. From 59 grab samples, we obtained 23 macrobenthic species of which six species were annelids $(26.1 \%$ of total species number), eight species were arthropods $(34.8 \%)$, nine species were mollusks $(39.1 \%)$. The researcher assessed abundance, biomass and the Shannon-Wiener, Pielou and Margalef diversity measures. We found the dominant species to be: Limnodrilus hoffmeisteri Claparede, Branchiura sowerbyi Beddard, Bellamya aeruginosa with distinctive differences in their distribution. Multivariate analyses (cluster analysis, multi-dimensional scaling) divided the samples into three communities which could be related to three regions. The biodiversity of the community of the upper reaches of rivers inside and out of Chaohu lake (community I) was the highest that of the lower reaches (community II) was the lowest that of Chaohu lake and its estuaries (community III) ranked in the middle. We also measured a suite of environmental variables. We employed canonical correspondence analysis to relate these with the macrofaunal community structure. Chlorophyll a and Nitrate levels were the most influential environmental factors.
\end{abstract}

Key words: Chaohu valley, macrobenthic, community characteristics, environmental factors, China

\section{INTRODUCTION}

Benthic animals are the aquatic fauna that spending all or most of their life on the bottom of a water body. They usually have a long, regional life span but weak migration ability and play an irreplaceable role in the material cycling and energy flow of aquatic ecosystems (Qu et al., 2007; Jiang et al., 2008). Because they vary in their adaptation to environmental conditions and their tolerance of or sensitivity to pollution, the parameters of benthic animals (such as their community structures, dominant species, diversity and abundance) can be used to reflect environmental quality.

Many studies in this field have been conducted both in China and globally. For example Sun et al. (2001) studied benthic animals in the South lake of Changchun and pointed out that they can reflect to some extent the lake's eutrophication and pollution levels. Jiang et al. (2008), Zhang et al. (2007) and Zhou et al. (2006) studied the relationships between different species of benthic vertebrates in different water bodies and various environmental factors. Beyene et al. (2009) used benthic macroinvertebrates as indicator species to reflect the pollution levels in water bodies. Located in the central part of Anhui province, Chaohu lake is one of China's five largest freshwater lakes (Fang and Wang, 2007). It lies between the Yangtze and Huaihe rivers and has many inflowing and outflowing rivers. In recent years due to the rapid development of industrialization and urbanization in the basin, the water body of Chaohu lake has undergone serious eutrophication and a series of eco-environmental problems such as the deterioration of water quality caused by cyanobacteria and the decline of the ecosystem in the lake (Fang and Wang, 2007; Xie et al., 2009; Zhao and Hu, 2009). Ecological evaluations of benthic community structure have been mainly confined to the Yangtze river, Taihu lake and Huaihe river basins (Jiang et al., 2008; Wu et al., 2008; Xia et al., 2006). Although there is much research into the pollution level of Chaohu lake, research into the benthic fauna has been limited (Deng et al., 2005; Wang and Yang, 2004) and there have been no reported ecological studies. Therefore, in this study, the researcher analyzed spatial distribution of the macrobenthos in Chaohu Lake Basin and the relationship of their distribution with environmental factors to help provide a biological basis for protection and control of water quality in the Chaohu Lake Basin.

Corresponding Author: Jiancai Deng, Graduate School of the Chinese, Academy of Science, Beijing 100039, China 


\section{MATERIALS AND METHODS}

Overview of the study area: The Chaohu Lake Basin is located in the central Anhui province between the Yangtze river and Huaihe river and is part of the Yangtze river system. It covers a area of about $13,000 \mathrm{~km}^{2}$ of which the upper region, north of the Chaohu Gate, totals $9,130 \mathrm{~km}^{2}$ across 6 counties (Hefei, Feixi, Shucheng, Lujiang, Chaohu and Feidong) and the area south of the Gate covers 4,365 $\mathrm{km}^{2}$ across three counties (Wuwei, Hexian and Hanshan).

Arrangement of sampling points: The ChaohuLake Basin has a dense, radial river system consisting of 33 rivers that directly or indirectly flow into the Chaohu lake. Seven of these rivers are large: the Zhegao, Nanfei, Paihe river, Hangbu, Baishishan, Yuxi and Zhaohe rivers.

In this study, a total of 59 sampling points were selected in the inflowing tributaries and in the lake body (Fig. 1). Among these points, 12 are in Chaohu lake, 9 in the Yuxi river, 6 in the Zhaohe and Baishishan rivers, 15 in the Hangbu and Fengle rivers, 13 in the Paihe and Nanfei rivers and 4 in the Zhegao river.

Sample collection and identification: Macrobenthos were sampled with an improved $1 / 40 \mathrm{~m}^{2}$ Peterson grab from March 17-25, 2010. A single sample was made at each site. The sediment samples were washed through 60 mesh nylon-membrane sieve. Material retained on the sieve was placed in white plates and the animal specimens were picked out by hand and preserved in a $10 \%$ Formalin solution. Specimens were identified in the laboratory to the lowest possible taxonomic level (Liu et al., 2003; Morse et al., 1994) counted and weighed. The results were eventually converted into density per unit area and wet weight biomass per unit area. Field indices were measured with a portable YSI water quality monitor. Nutrient levels and macrobenthos species and biomass were determined in accordance with the Evaluation Standards for Lake Eutrophication (Jin and Tu, 1990).

Data analysis: Macrobenthic communities were classified with cluster analysis and Multidimensional Scaling (MDS) based on Bray-Curtis similarity coefficient (Ma et al., 1997; Zhou and Zhang, 2003; Clarke and Warwick, 1994; Clarke and Green, 1988) using the past1. 94 statistical software. The following species diversity indices were selected: Shannon-Wiener Index:

$$
\mathrm{H}^{\prime}=-\sum_{\mathrm{i}=1}^{s} \mathrm{P}_{\mathrm{i}} \ln \mathrm{P}_{\mathrm{i}}
$$

Pielou evenness index:

$$
\mathrm{J}=\mathrm{H}^{\prime} / \log _{2} \mathrm{~S}
$$

Margalef richness index:

$$
\mathrm{D}=(\mathrm{S}-1) / \ln \mathrm{N}
$$

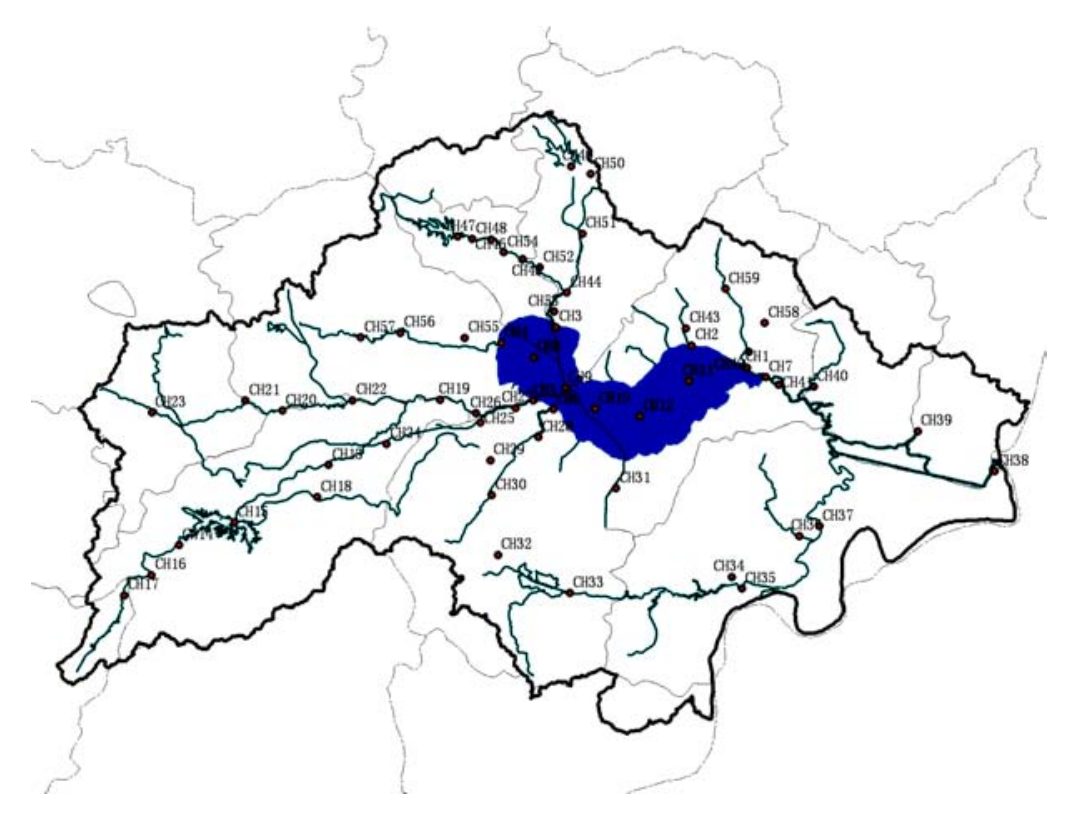

Fig. 1: Map of sampling points in the Chaohu Lake Basin 
In these equations, $\mathrm{S}$ referred to the total number of species, $\mathrm{P}_{\mathrm{i}}$ the proportion of the number of individuals in Species $i$ to the total number of individuals and $\mathrm{N}$ the total number of individuals of all species. The software CANOCO (Version 4.5) was used for Canonical Correspondence Analysis (CCA). The species data were maximally standardized and environmental factors were analyzed using SPSS 15.0 software and maximally standardized after outliers had been eliminated.

\section{RESULTS AND DISCUSSION}

Species composition of macrobenthos: In the survey, macrobenthos were identified in 38 of the 59 sampling points: 12 points in Chaohu lake, eight points in Hangbu river, six points in Yuxi river, five points in Nanfei river, three points in Zhegao river, two points in Paihe river and two points in Baishishan river.

A total of 23 species of macrobenthos were identified (Table 1) of which six species are classified as Annelida; eight species as Arthropoda and nine species as Mollusca.

Occurrence frequency and biomass of macrobenthos: Table 1 shows the occurrence frequency, abundance and biomass of macrobenthos in the samples from the Chaohu Lake Basin.

At the time of sampling, the annelids Limnodrilus hoffmeisteri and Branchiura sowerbyi and the mollusc Bellamya aeruginosa were the dominant species (in terms of occurrence frequency in samples) of macrobenthos in the basin. Limnodrilus hoffmeisteri with an occurrence frequency of $40.7 \%$ has also the highest mean abundance of 1,840 ind $\mathrm{m}^{-2}$ and the highest average biomass of $\left(5.4 \mathrm{~g} \mathrm{~m}^{-2}\right)$ of all species except molluses.

Branchiura sowerbyi although, ranking second in terms of occurrence frequency $(23.7 \%)$ and biomass (1.7 $\mathrm{g} \mathrm{m}^{-2}$, excepting molluses) has a relatively low average abundance. Bellamya aeruginosa with an occurrence frequency of $20.3 \%$ (ranking third) and an average biomass of $87.5 \mathrm{~g} \mathrm{~m}^{-2}$ (ranking second) also has a relatively low abundance of 65.3 ind $\mathrm{m}^{-2}$. All other species of macrobenthos occurred in $<10 \%$ of the samples, possibly indicating localized distribution in the Chaohu Lake Basin.

The standard deviations abundance and biomass of some species of macrobenthos over their occurrence area are much larger than the means and the means are greater than the medians (e.g., for abundance of Limnodrilus hoffmeisteri the standard deviation $\left(5,203.0\right.$ ind $\left.\mathrm{m}^{-2}\right)$ is 2.8 times the mean $\left(1,840\right.$ ind $\left.\mathrm{m}^{-2}\right)$ which is 59.1 times the median ( 88 ind $\mathrm{m}^{-2}$ ). Additionally, some macrobenthic species such as Nephtys oligobranchia, Chaoborus, Arconaiai lanceolata and Anodonta were identified in only one sampling point so there are no standard deviations. These deviations indicate significant spatial differences of macrobenthos distribution in the Chaohu Lake Basin.

Spatial distribution of abundance and biomass of main dominant species: Both the annelid Limnodrilus hoffmeisteri and the mollusc Bellamya aeruginosa have

Table 1: Occurrence frequency and biomass of macrobenthos

\begin{tabular}{|c|c|c|c|c|c|c|}
\hline Phylum & Name of species & Occurrence frequency $(\%)$ & Abundance (ind. $\mathrm{m}^{-2}$ ) & Median & Biomass $\left(\mathrm{g} \mathrm{m}^{-2}\right)$ & Median \\
\hline \multirow[t]{6}{*}{ Annelida } & Nephtys oligobranchia & 1.7 & $16 \pm$ & 16 & $0.03 \pm$ & 0.03 \\
\hline & Teneridrilus mastix & 3.4 & $96 \pm 45.25$ & 96 & $0.02 \pm 0.01$ & 0.02 \\
\hline & Limnodrilus hoffmeisteri Claparède & 40.7 & $1840 \pm 5203.02$ & 88 & $5.44 \pm 12.38$ & 0.12 \\
\hline & Limnodrilus grondisetosus Nomura & 6.8 & $36 \pm 30.29$ & 24 & $0.07 \pm 0.06$ & 0.07 \\
\hline & Branchiura sowerbyi Beddard & 23.7 & $58.29 \pm 94.05$ & 16 & $1.66 \pm 3.48$ & 0.32 \\
\hline & Rhyacodrilus sinicus & 6.8 & $864 \pm 1003.21$ & 600 & $0.38 \pm 0.43$ & 0.30 \\
\hline \multirow[t]{8}{*}{ Arthropod } & Tonypus chinensis & 6.8 & $72 \pm 101.61$ & 24 & $0.34 \pm 0.55$ & 0.08 \\
\hline & Glyptotendipes sp. & 6.8 & $68 \pm 63.16$ & 56 & $0.05 \pm 0.04$ & 0.03 \\
\hline & Clinotonypus sp. & 3.4 & $16 \pm 0$ & 16 & $0.06 \pm 0.01$ & 0.06 \\
\hline & Propsilocerus akamusi & 6.8 & $144 \pm 187.05$ & 80 & $1.52 \pm 2.84$ & 0.15 \\
\hline & Proclakius sp. & 5.1 & $16 \pm 0$ & 16 & $0.06 \pm 0.02$ & 0.05 \\
\hline & Microchironomus sp. & 1.7 & $80 \pm 90.51$ & 80 & $0.01 \pm 0.01$ & 0.01 \\
\hline & Chaoborus sp. & 1.7 & $16 \pm$ & 16 & $0.01 \pm$ & 0.01 \\
\hline & Chironomus plumosus & 6.8 & $76 \pm 76.59$ & 56 & $0.25 \pm 0.39$ & 0.08 \\
\hline \multirow[t]{9}{*}{ Mollusc } & Porafossarulus eximius & 3.4 & $24 \pm 11.31$ & 24 & $20.05 \pm 5.46$ & 20.05 \\
\hline & Semisulcospira cancellata & 6.8 & $16 \pm 0$ & 16 & $5.96 \pm 2.90$ & 5.41 \\
\hline & Corbicula fluminea & 6.8 & $52 \pm 42.08$ & 48 & $162.94 \pm 156.64$ & 115.52 \\
\hline & Bellanya aeruginosa & 20.3 & $65.33 \pm 63.07$ & 24 & $87.48 \pm 87.63$ & 59.39 \\
\hline & Lamprotula leai & 5.1 & $16 \pm 0$ & 16 & $471.15 \pm 292.27$ & 554.56 \\
\hline & Arconaia lanceolata & 1.7 & $16 \pm$ & 16 & $789.92 \pm \backslash$ & 789.92 \\
\hline & Parafossarulus striatulus Benson & 3.4 & $16 \pm 0$ & 16 & $3.12 \pm 0.37$ & 3.12 \\
\hline & Anodonta sp. & 1.7 & $32 \pm$ & 32 & $57.12 \pm$ & 57.12 \\
\hline & Unio douglasiae & 5.1 & $32 \pm 16.00$ & 32 & $214.99 \pm 108.07$ & 179.62 \\
\hline
\end{tabular}

The data in the table of the density and biomass are mean \pm standard deviation 
the relatively high occurrence frequencies in the Chaohu Lake Basin. The abundance and biomass distributions of these species in the basin are shown in Fig. 2 with some differences apparent.

The basin has a total of seven river systems: Zhegao river, Nanfei river, Hangbu river, Fengle river, Baishishan river, Paihe river and Yuxi river. Figure 2 shows that Limnodrilus hoffmeisteri was mainly found in Nanfei river and its estuary to the lake and sometimes in Paihe river and its estuary to the lake. Limnodrilus hoffmeisteri has low biomass in the lake body but was not identified in other areas of the basin.

Gong et al. (2001) found in their study of the East lake in Wuhan that macrobenthic species diversity is usually inversely related to the water body's nutrient level. In this survey, Limnodrilus hoffmeisteri were identified in 24 sampling points but its density in Nanfei river was much higher than in other areas of the basin.

Here it accounts for $91.6 \%$ of the total number of macrobenthos in the samples. Such low biological diversity indicates that Nanfei river has become eutrophicated. Nanfei river has been severely polluted because of water shortages, the discharge of industrial wastewater and mostly untreated municipal sewage
(Ji et al., 2006; Sheng et al., 2007) organic pollutants have been identified as the main cause of water pollution in this river. It can also be shown in Fig. 2 that the abundance and biomass of Limnodrilus hoffmeisteri in the western part of Chaohu lake are higher than in the eastern lake body this may be attributed to Nanfei river.

The abundance and biomass of Bellamya aeruginosa are relatively low in Nanfei river and Paihe river (Fig. 2). Deng et al. (2005) showed in their studies of Chaohu lake that both the abundance and biomass of Bellamya species decreased with the development of water eutrophication. These low abundance and biomass levels may be attributed to the rather heavy pollution of Nanfei and Paihe rivers. Bellamya aeruginosa is also distributed in the lake and other major tributaries. Bellamya aeruginosa adults live at the lake bottom and feed on benthic algae, some bacteria and organic detritus in the silt so they are highly adaptable and occupy a wide niche (Cai et al., 2009).

\section{Characteristics of macrobenthic communities in the Chaohu Lake Basin}

Structures of macrobenthic communities in the Chaohu

Lake Basin: The Fig. 3 shows the dendrogram from the cluster analysis and the MDS plot. The macrobenthos in the Chaohu Lake Basin are mainly distributed in three
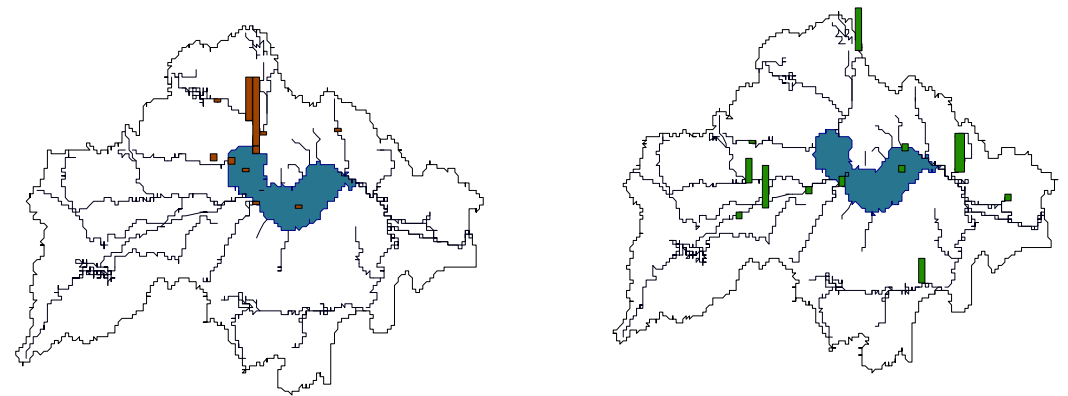

『 Number of mnod 10,000 $\square \mathrm{D}$

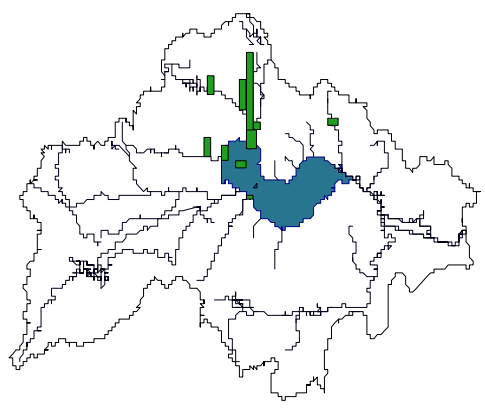

1. Biomass of mnod 15 $\square \mathrm{F}$

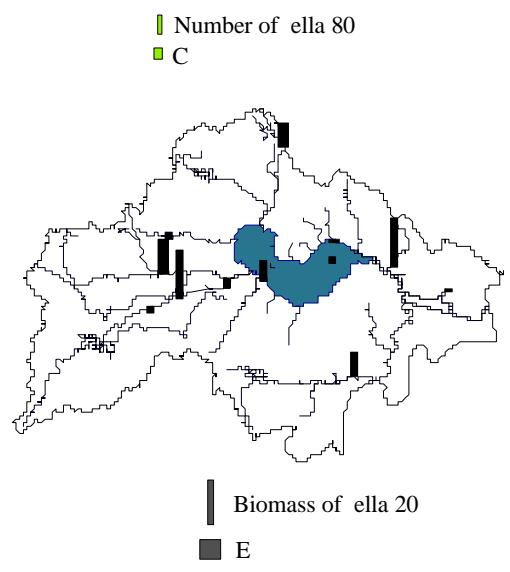

Fig. 2: Spatial distribution of limnodrilus hoffmeisteri and Bellamya aeruginosa in the Chaohu Lake Basin 

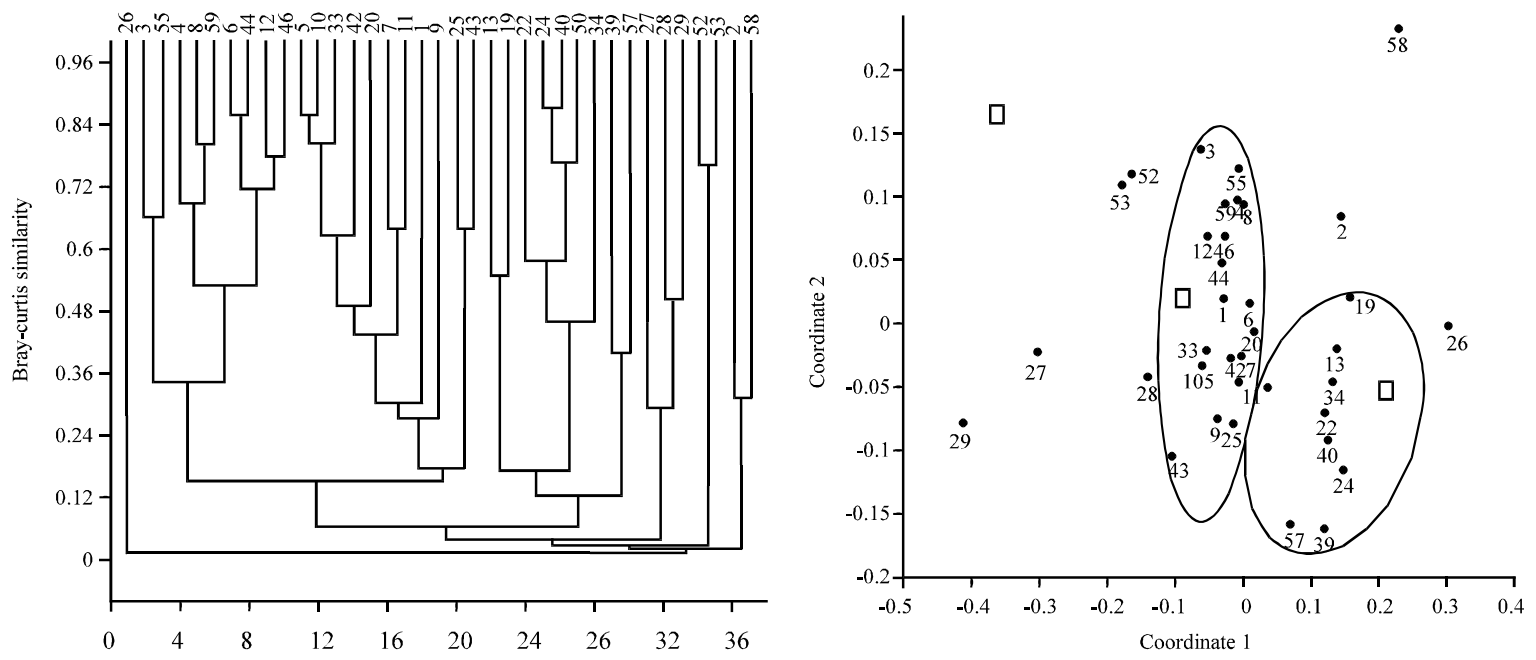

Fig. 3: Dendrogram from cluster analysis and multidimensional scaling ordination plot of samples based on macrofaunal species abundances

Table 2: Biodiversity of macrobenthic communities in the Chaohu Lake Basin

\begin{tabular}{|c|c|c|c|c|c|c|c|c|c|c|c|}
\hline Community & $\begin{array}{c}\text { Sampling } \\
\text { site }\end{array}$ & $\begin{array}{c}\text { The number } \\
\text { of species }\end{array}$ & $\mathrm{H}^{\prime}$ & $\mathrm{J}$ & $\mathrm{D}$ & Community & $\begin{array}{c}\text { Sampling } \\
\text { site }\end{array}$ & $\begin{array}{c}\text { The number } \\
\text { of species }\end{array}$ & $\mathrm{H}^{\prime}$ & $\mathrm{J}$ & $\mathrm{Dd}$ \\
\hline \multirow[t]{10}{*}{$\mathrm{I}$} & CH 13 & 4 & 1.13 & 0.36 & 0.57 & III & CH1 & 3 & 0.86 & 0.28 & 0.36 \\
\hline & CH 19 & 5 & 1.36 & 0.43 & 0.79 & - & $\mathrm{CH} 3$ & 1 & 0.00 & 0.00 & 0.00 \\
\hline & $\mathrm{CH} 22$ & 4 & 1.07 & 0.34 & 0.62 & - & $\mathrm{CH} 4$ & 2 & 0.23 & 0.07 & 0.14 \\
\hline & CH 24 & 2 & 0.30 & 0.10 & 0.19 & - & CH 5 & 1 & 0.00 & 0.00 & 0.00 \\
\hline & CH 34 & 5 & 1.42 & 0.45 & 0.70 & - & $\mathrm{CH} 6$ & 3 & 0.56 & 0.18 & 0.35 \\
\hline & CH 39 & 2 & 0.64 & 0.20 & 0.26 & - & $\mathrm{CH} 7$ & 4 & 1.20 & 0.38 & 0.55 \\
\hline & $\mathrm{CH} 40$ & 3 & 0.57 & 0.18 & 0.38 & - & $\mathrm{CH} 8$ & 4 & 0.74 & 0.24 & 0.46 \\
\hline & CH 50 & 5 & 1.13 & 0.36 & 0.72 & - & $\mathrm{CH} 9$ & 3 & 1.10 & 0.35 & 0.52 \\
\hline & CH 57 & 2 & 0.69 & 0.22 & 0.29 & - & $\mathrm{CH} 10$ & 2 & 0.56 & 0.18 & 0.24 \\
\hline & - & - & - & - & - & & CH 11 & 3 & 0.97 & 0.31 & 0.41 \\
\hline \multirow[t]{10}{*}{ II } & $\mathrm{CH} 2$ & 4 & 1.11 & 0.36 & 0.52 & - & $\mathrm{CH} 12$ & 3 & 0.79 & 0.25 & 0.32 \\
\hline & $\mathrm{CH} 26$ & 1 & 0.00 & 0.00 & 0.00 & - & CH 20 & 4 & 1.17 & 0.37 & 0.59 \\
\hline & $\mathrm{CH} 27$ & 2 & 0.50 & 0.16 & 0.23 & - & $\mathrm{CH} 25$ & 4 & 1.09 & 0.35 & 0.59 \\
\hline & CH 28 & 3 & 1.10 & 0.35 & 0.52 & - & CH 33 & 1 & 0.00 & 0.00 & 0.00 \\
\hline & CH 29 & 1 & 0.00 & 0.00 & 0.00 & - & $\mathrm{CH} 42$ & 4 & 1.24 & 0.40 & 0.66 \\
\hline & CH 52 & 2 & 0.26 & 0.08 & 0.10 & - & $\mathrm{CH} 43$ & 2 & 0.29 & 0.09 & 0.19 \\
\hline & CH 53 & 2 & 0.30 & 0.10 & 0.10 & - & $\mathrm{CH} 44$ & 2 & 0.22 & 0.07 & 0.18 \\
\hline & CH 58 & 1 & 0.00 & 0.00 & 0.00 & - & $\mathrm{CH} 46$ & 1 & 0.00 & 0.00 & 0.00 \\
\hline & - & - & - & - & - & - & CH 55 & 4 & 0.92 & 0.29 & 0.39 \\
\hline & - & - & - & - & - & - & CH 59 & 1 & 0.00 & 0.00 & 0.00 \\
\hline
\end{tabular}

community regions. Region I samples are mainly distributed in the upper reaches of the major inflowing rivers, Region II samples in the lower reaches of major inflowing rivers and Region III samples in the body of Chaohu lake and estuaries of main inflowing rivers. It can be seen that according to the distribution pattern of macrobenthos, the Chaohu Lake Basin is divided into three annular domains with the lake body as the center. Region I has nine samples where 13 species of macrobenthos were identified and this region has a low abundance proportion of Limnodrilus hoffmeisteri but the highest proportion of Bellamya aeruginosa. Region II has a total of eight samples where nine species of macrobenthos were identified. This region has a higher abundance proportion of Limnodrilus hoffmeisteri than Region I. Region III has a total of 20 sample points where
19 species of macrobenthos were identified and this region has a higher abundance proportion of Limnodrilus hoffmeisteri than that of other macrobenthic species.

Biodiversity of macrobenthic communities in the Chaohu Lake Basin: The diversity indexes of all sampling points are shown in Table 2. Averaging for each region: the means of Shannon-Wiener diversity index $(\mathrm{H})$ are $0.923 \pm 0.386,0.409 \pm 0.465$ and $0.597 \pm 0.466$ in Region I, II and III, respectively; the mean values of Pielou evenness index $(\mathrm{J})$ are $0.293 \pm 0.122,0.131 \pm 0.149$ and $0.191 \pm 0.149$ in the three regions, respectively the mean values of Margalef richness index (D) are $0.502 \pm 0.225,0.184 \pm 0.221$ and $0.298 \pm 0.226$ in the three regions, respectively.

It can be seen from the table that Region I has the highest mean values of these three types of indices, 
Region III comes second and Region II ranks third. Statistical analysis shows that between Region I and Region II, all three indexes are significantly different ( $\mathrm{p}$ values for $\mathrm{H}^{\prime}, \mathrm{J}$ and $\mathrm{D}$ are $0.024,0.026$ and 0.006 , respectively) but are not significantly different between Region I and Region $\mathrm{II}$ ( $\mathrm{p}$ values for $\mathrm{H}^{\prime}, \mathrm{J}$ and $\mathrm{D}$ are 0.079 , 0.082 and 0.030 , respectively) or between Region II and Region III ( $\mathrm{p}$ values for $\mathrm{H}^{\prime}, \mathrm{J}$ and $\mathrm{D}$ are $0.323,0.329$ and 0.234 , respectively).

These values in combination with the community structure analysis conducted with Bray-Curtis similarity coefficient clustering and Multidimensional Sorting scale (MDS) reflect the situation of water quality in the Chaohu Lake Basin. The middle and lower reaches of major inflowing rivers are most influenced by human activities and consequently have the worst water quality. Under the same influences, the lake body and the estuaries of inflowing rivers also have relatively poor water quality. The upper reaches of the inflowing rivers especially in the mountainous areas of south Anhui province where human influence is relatively weak have the best water quality and consequently the greatest values for species diversity, species evenness and species richness indices. Wang et al. (2007) conducted a quantitative analysis of the eco-environmental quality of Chaohu Lake Basin and considered that Lu'an had the best eco-environmental quality followed by Hefei and Chaohu lake had the worst quality in the three sub-basins.

Their results were different from this study because their evaluations were on the basis of three aspects: society, economy and environment whereas this study only considers the factor of environment and reflects that the upper reaches of the basin has a relatively good ecological environment and the lower reaches and the lake body has a poor ecological environment.

Relationship of macrobenthos distribution with environmental factors: Because different macrofaunal species respond differently to environmental conditions and have different levels of tolerance of and sensitivity to pollution levels, the parameters such as their community structure, dominant species, diversity and biomass can be used to indicate environmental characteristics. The relationship between 28 species of macrobenthos and 13 environmental factors were analyzed with $\mathrm{CCA}$ and shown in Fig. 4.

The eigenvalues of the first two ordination axes are 0.805 and 0.667 , respectively in the sorting graph and the correlation coefficients between the first two species of ordination axes and environmental factors are 0.923 and 0.842 , respectively. The first two ordination axes show the cumulative contribution rate of the species

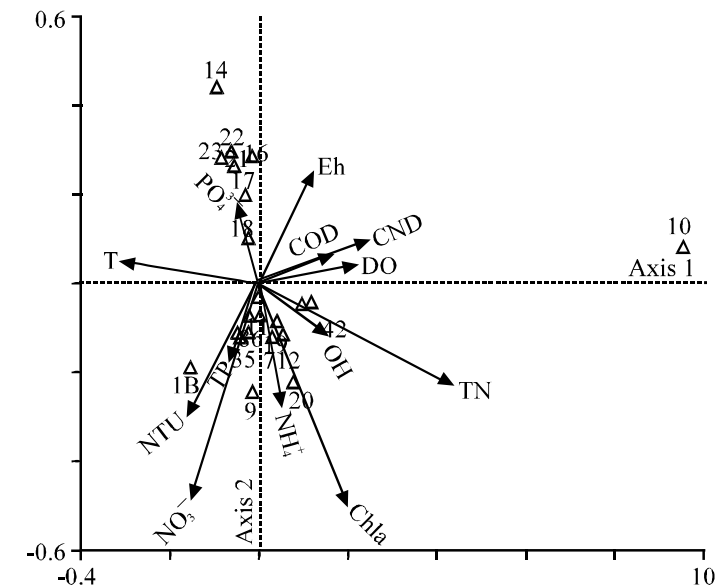

Fig. 4: CCA sorting of 23 species of macrobenthos and environmental factors in the Chaohu Lake Basin (the series numbers in the figure represents the species of macrobenthos shown in Table 1) $\mathrm{T}$ : Temperature, CND: Conductivity, Eh: Oxidationreduction potential, NTU: turbidity, Chla: Chlorophyll, DO: Dissolved Oxygen, TN: Total Nitrogen, TP: Total Phosphorus, $\mathrm{PO}_{4}{ }^{3-}$ : Phosphate, $\mathrm{NH}_{4}^{+}$: Ammonium, $\mathrm{NO}_{3}^{-}$: nitrate, $\mathrm{COD}$ : Chemical Oxygen Demand

distribution is $16.1 \%$, the relationship between the species and the environment is $43.9 \%$ and the correlation between Ordination axis 1 and Ordination axis 2 is quite small $(-0.0035)$ indicating that the sorting graph can reflect the relationship between the species of macrobenthos and environmental factors (Ter Braak, 1986). In the CCA sorting graph, the environmental factors are shown as line segments (vectors) with an arrow and the length of the line indicates the magnitude of the relationship between the species distribution and environmental factors (Cao et al., 2000). It can be seen that Chla and $\mathrm{NO}_{3}{ }^{-}$are the environmental factors most influential to the macrobenthos in the basin. Liu et al. (2003) in their studies on the Pearl and Liuxi rivers showed that the abundance of macrobenthos species showed a significantly negative correlation with $\mathrm{NO}_{3}{ }^{-}-\mathrm{N}$ levels at the river bottom consistent with these results.

\section{CONCLUSION}

In the survey areas of the Chaohu Lake Basin, a total of 23 species of macrobenthos were identified of which 6 species were Annelida, accounting for $26.1 \%$ of the total; 8 species were arthropod, accounting for $34.8 \%$ and 9 species were mollusca, accounting for $39.1 \%$. Based on frequency of occurrence, the annelids Limnodrilus 
hoffmeisteri and Branchiura sowerbyi and the mollusc Bellamya aeruginosa are the dominant species of macrobenthos in the Chaohu Lake Basin and Limnodrilus hoffmeisteri is the main pollution-tolerant species in the basin. The macrobenthos are distributed in the basin with significant spatial differences.

Combination of multivariate analysis with analysis of species diversity indices divides the Chaohu Lake Basin into three regions in terms of water quality: the upper reaches of all major inflowing rivers (best water quality), the body of Chaouh lake and its inflowing estuaries (medium water quality) and the middle and lower reaches of all major inflowing rivers (worst water quality). Chla and $\mathrm{NO}_{3}{ }^{-}$are the most significant environmental factors influencing the distribution of macrobenthos.

\section{ACKNOWLEDGEMENT}

This research was jointly funded by China National Fund for Water Pollution Control and Management project (No.2008ZX07101-012, 2008ZX07526-002-08).

\section{REFERENCES}

Beyene, A., T. Addis, D. Kifle, W. Legesse, H. Kloos and L. Triest, 2009. Comparative study of diatoms and macroinvertebrates as indicators of severe water pollution: Case study of the Kebena and Akaki rivers in Addis Ababa, Ethiopia. Ecological Indicators, 9: 381-392.

Cai, Y.J., Z.J. Gong and B.Q. Qin, 2009. Standing crop and spatial distributional pattern of Mollusca in Lake Taihu. J. Lake Sci., 21: 152-159.

Cao, T., S. Guo and C. Gao, 2000. Ordination analysis on relationship between bryophyte distribution and climatic factors. Chinese J. Applied Ecol., 11: 680-686.

Clarke, K.R. and R.H. Green, 1988. Statistical design and analysis for a biological effect study. Mar. Ecol. Prog. Ser., 46: 213-226.

Clarke, K.R. and R.M. Warwick, 1994. Change in Marine Communities: An Approach to Statistical Analysis and Interpretation. Plymouth Marine Laboratory, UK.

Deng, D., H. Li, W. Hu, Q. Zhou and L. Guo, 2005. Effects of eutrophication on distribution and population density of Corbicula fluminea and Bellamya sp. in ChaohuLake. Chinese J. Applied Ecol., 16: 1502-1506.

Fang, C.X. and C.X. Wang, 2007. Environmental Geochemistry and Eutrophication of Lakes of MiddleLower Reaches of the Yangtze River. Science Press, Beijing.

Gong, Z.J., P. Xie, H.Z. Tang and S. Wang, 2001. The influence of eutrophycation upon community structure and biodiversity of macrozoobenthos. Acta Hydrobiol. Sinica, 25: 210-216.
Ji, L., L.W. Yang and J. Li, 2006. Study on pollution situation of Nanfeihe river and strategies of sustainable development. J. Anhui Univ. Nat. Sci. Edn., 30: 91-94.

Jiang, W.X., Q.H. Cai, T. Tang, N.C. Wu, X.C. Fu, F.Q. Li and R.Q. Liu, 2008. Spatial distribution of macroinvertebrates in Xiangxi River. Chinese J. Applied Ecol., 19: 2443-2448.

Jin, X.C. and Q.Y. Tu, 1990. The Criterion of Eutrophic Lake Survey. China Environmental Science Press, Beijing.

Liu, Y., J.E. Vermaat, E.D. de Ruyter and K. de Ham, 2003. The Correlation between macrofauna distribution and nitrogen as well as phosphors in the Pearl River and the Liuxi River. Acta Scientiarum Naturalium Universitatis Sunyatseni, 42: 95-99.

Ma, Z.Y., H. Liu and H.Q. Wang et al., 1997. Multivariate analysis of community structure on macrobenthos. China Environ. Sci., 17: 297-300.

Morse, J.C., L.F. Yang and L.X. Tian, 1994. Aquatic insects of China useful for monitoring water quality. Hohai University Press, Nanjing.

Qu, X.D., M. Cao, M.L. Shao, D.F. Li and Q.H. Cai, 2007. Macrobenthos in Jinping reach of Yalongjiang River and its main tributaries. Chinese J. Applied Ecol., 18: $158-162$.

Sheng, Z.J., S.Q. Sun, J.C. Wang X.D. Ni and W. Chu, 2007. Comprehensive evaluation of river water environmental quality based on the principal component analysis. Environ. Sci. Manage., 32: 172-175.

Sun, G., L. Sheng and M. Li, 2001. Community characteristics of benthonic animals and its relationship to environmental factors in the Nanhu Lake, Changchun. Chinese J. Applied Ecol., 12: $319-320$.

Ter Braak, C.J.F., 1986. Canonical Correspondence Analysis: A New Eigenvector Technique for Multivariate Direct Gradient Analysis. Ecology, 67: $1167-1179$.

Wang, B.X. and L.F. Yang, 2004. A study on tolerance values of benthic macroinvertebrate taxa in eastern China. Acta Ecologica Sinica, 24: 2768-2775.

Wang, S.G., J.X. Huang and L.S. Zha, 2007. Analysis quantitatively on eco-environmental quality of Chaohu Basin. Resour. Dev. Market, 23: 987-988.

Wu, S., J. Jing, W.F. Ni, X.Y. Li and Y.Y. Jun, 2008. Community structures of macrozoobenthos and bioassessment of water quality in Tanqigou Stream of Qingjiang River Basin, Hubei Province. J. Lake Sci., 20: $520-528$. 
Xia, A.J., X.H. Chen, Y.X. Cai, G. Peng and M.H. Wang, 2006. The status of zoobenthos community structure and preliminary evaluation of water quality in the Jiangsu section of the Yangtze River. Mar. Fish., 28: $272-277$.

Xie, X.Y., X. Qian and Y.C. Zhang, 2009. Effect on Chaohu lake water environment of water transfer from Yangtze River to Chaohu Lake. Res. Environ. Sci., 22: 897-901.

Zhang, Y., Z.N. Zhang, Y. Huang and E. Hua, 2007. Abundance and biomass of meiobenthos in Southern Yellow Sea in winter. Chinese J. Applied Ecol., 18: 411-419.
Zhao, H.Q. and Z.Q. Hu, 2009. Evaluation of eutrophication and its remediation countermeasures in the East-half of Chaohu Lake. J. Hydroecol., 2: $119-122$.

Zhou, H. and Z.N. Zhang, 2003. Rationale of the multivariate statistical software primer and its application in benthic community ecology. J. Ocean Univ. Qingdao, 33: 58-66.

Zhou, X., Z. Ge, W. Shi, T. Wang, D. Cao and L. Zhou, 2006. Seasonal fluctuation of macrobenthos community in Jiuduansha intertidal wetland of Yangtze River Estuary. Chinese J. Applied Ecol., 17: 2079-2083. 